\title{
Ganglioglioneurocytoma of the Posterior Fossa
}

\author{
Ahmed M. Alkhani, Juan M. Bilbao, Paul Medline and Fadegbola A. Ogundimu
}

\begin{abstract}
Objective and Importance: Ganglioglioneurocytoma is not yet a well defined clinical and histopathological entity; recent reports outline the histopathological features of this very rare trimorphous tumor, under different names with its basic components of gangliocytoma, neurocytoma and glioma. Four previous reports described this tumor in eleven patients. This is the first case report describing ganglioglioneurocytoma in the posterior fossa. Clinical Presentation and Intervention: A 31-year old male with midline posterior fossa ganglioglioneurocytoma is described, providing the neuroimages and histopathological studies. Conclusion: Ganglioglioneurocytoma is a rare mixed neuronal and glial tumor that can also occur in the posterior fossa.
\end{abstract}

\begin{abstract}
RÉSUMÉ: Ganglioglioneurocytome de la fosse postérieure. Objectif et importance: Le ganglioglioneurocytome est encore une entité clinique et histopathologique mal définie. Des rapports récents décrivent sous des noms différents les caractéristiques histopathologiques de cette tumeur très rare, possédant trois composantes de base, le gangliocytome, le neurocytome et le gliome. Quatre rapports antérieurs décrivent cette tumeur chez onze patients. Nous présentons le premier cas d'un ganglioglioneurocytome de la fosse postérieure. Présentation clinique et interven. tion: Nous décrivons le cas d'un homme âgé de trente et un ans porteur d'un ganglioglioneurocytome médian de la fosse postérieure et nous en présentons la neuro-imagerie et l'anatomopathologie. Conclusion: Le ganglioglioneurocytome est une tumeur mixte neuronale et gliale rare qui peut également être localisée dans la fosse postérieure.
\end{abstract}

Can. J. Neurol. Sci. 1999; 26: 207-210

Mixed cell tumors in the CNS containing both glial and neuronal elements are rare. Gangliogliomas account for about $1 \%$ of all brain neoplasms, which usually present with seizures in children. They have been reported in all levels of the neuroaxis, but were more common in the temporal lobe. The tumor contains a glial component usually astrocytic of variable cellularity and a ganglionic component of large often binucleated neurons scattered or in clusters that immunostain with synaptophysin and chromogranin. These tumors usually have a good prognosis following surgical resection.'

Central neurocytomas are rare tumors of the CNS, classically affect young adults, and arise in the lateral ventricles near the foramen of Monro. However, they have been reported away from the ventricles, ${ }^{2}$ in the cerebellum ${ }^{3}$ and in the spinal cord. ${ }^{4}$ The tumor consists of neurocytes; small round cells with perinuclear halo formation and stain with synaptophysin. Under the electron microscope, neurosecretory granules in the perinuclear cytoplasm and neurites are characteristic. This neoplasm is usually curable with total resection whenever possible. Glioneurocytomas are another mixed tumor with glial and neurocytic components. They have been reported with similar clinical and pathological findings. ${ }^{5}$

Nashio et al. in 1990 were the first to describe a tumor with well differentiated gangliocytes and neurocytes in the lateral ventricle. ${ }^{6}$ Since then, a total of eleven cases were reported describing tumors with such a morphology, usually associated with glial component of well differentiated astrocytes. In this paper we describe the 12th case, which to our knowledge is the first to be reported arising in the posterior fossa.

\section{Case Report}

A 25 -year-old previously healthy male presented with a one year history of progressive headache and blurring of vision. Physical exam showed papilloedema and ataxic gait but normal cranial nerve function. CT scan images revealed a midline posterior fossa mass at the level of the fourth ventricle with a large dorsal cystic component and a smaller solid ventral component with calcification. The solid mass partially enhanced with IV contrast. It seemed to originate from the cerebellum and compressed the fourth ventricle causing obstructive hydrocephalus (Figure 1). The patient underwent surgery for gross total resection and had an uneventful recovery. Postoperative images showed only small residual calcifications. He had ventriculo-peritoneal shunt for hydro-

From the Division of Neurosurgery (AMA) and Division of Neuropathology (JMB), University of Toronto, Toronto, Ontario, Canada, Department of Pathology (PM) and Department of Neurosurgery (FAO), Sudbury General Hospital, Sudbury, Ontario, Canada.

RECEIVED AUGUST 27, 1998. ACCEPTED IN FINAL FORM APRIL 16, 1999. Reprint requests to: Dr. Ahmed Alkhani, The Toronto Hospital, Toronto Western Division, Division of Neurosurgery, 399 Bathurst Street, Toronto, Ontario, Canada M5T 2S8 


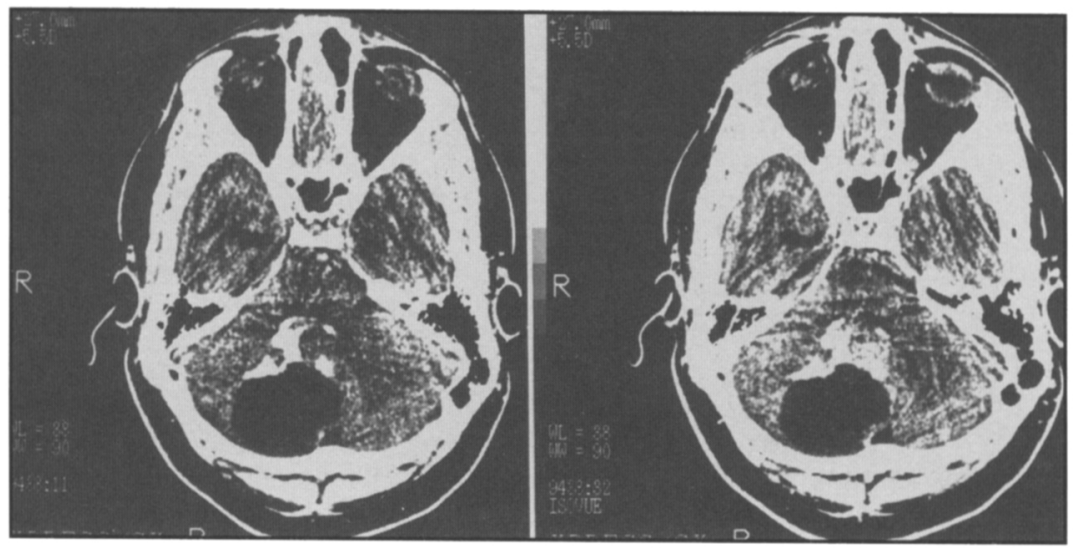

Figure 1: CT of the head showing the posterior fossa midline lesion without (left) and with contrast (right).

cephalus. In an eighteen months post-operative follow up, he continued symptom free, with no radiological evidence of tumor recurrence.

\section{Histopathological studies:}

H\&E staining of the paraffin sections showed the tumor to be composed of large mature-looking neurons often binucleated, scattered in the field in a pattern resembling gangliocytomas, and large aggregations of small round cells with perinuclear halos. There was a proliferation of moderately pleomorphic astrocytes with the formation of Rosenthal fibers (Figure 2). Mitotic activity was exceptional, microcystic changes and microcalcification were noted.

The immunostaining profile of the tumor was helpful in identifying the different cell types. Synaptophysin stained the larger binucleated ganglion cells and the small rounded neurocytes, with the typical immunostaining pattern on the cell surface as shown in Figure 3. Neuron specific enolase (NSE) and neurofilaments highlighted both gangliocytes and neurocytes. Only the large ganglion cells immunoreacted to chromogranin A (Figure 3). Glial fibrillary acidic protein (GFAP) stained the glial part of the tumor and only showed minor reaction in the background of the small cells population.

\section{Discussion}

Various dimorphic mosaics have been recognized arising from the three basic cells components: gangliocytes, neurocytes and astrocytes, These tumors are known as ganglioglioma, ganglioneurocytoma and glioneurocytoma. The presence of the three neoplastic elements in the same tumor is rare. We identified four reports in the literature describing a total of eleven cases, all with the essential histopathological features of ganglioglioneurocytoma (Table). In 1990 Nishio et al. were the first to describe a tumor with such morphology in a 30-year-old female with intraventricular tumor. ${ }^{6}$ The term ganglioglioneurocytoma was first used by Miller et al. in 1992 to describe four cases of a tumor demonstrating these features. Further illustration of these cases was published later. ${ }^{1,4,7}$ More recently Giangaspero et al. demonstrated the pathological findings in five cases from total of 11 with neurocytoma. ${ }^{8}$ At the same time Schweitzer and Davies

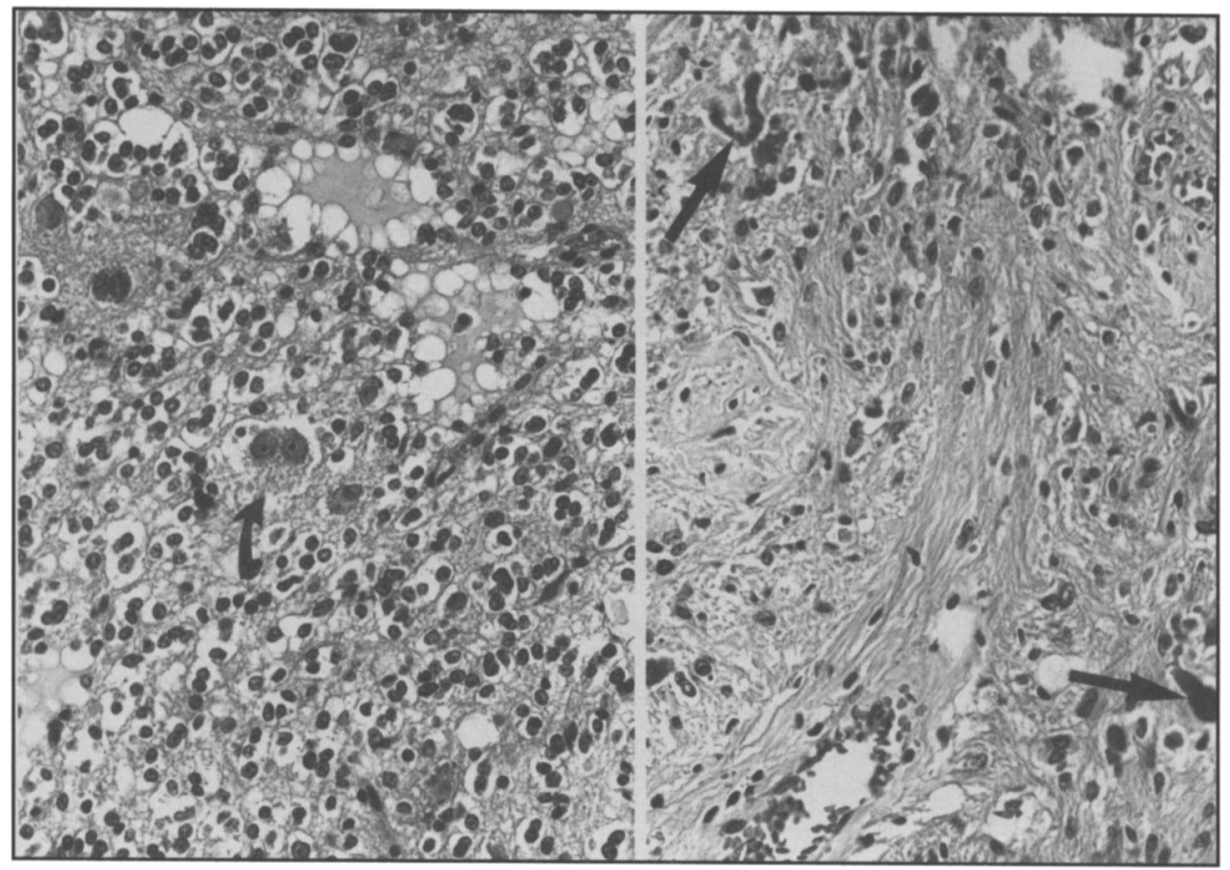

Figure 2: Left: H\&E section illustrating the large binucleated cells (curved arrow) and the small neurocytes with halo formation. Right: $H \& E$ section of the pilocytic astrocytes with Rosenthal fibres (arrows). 


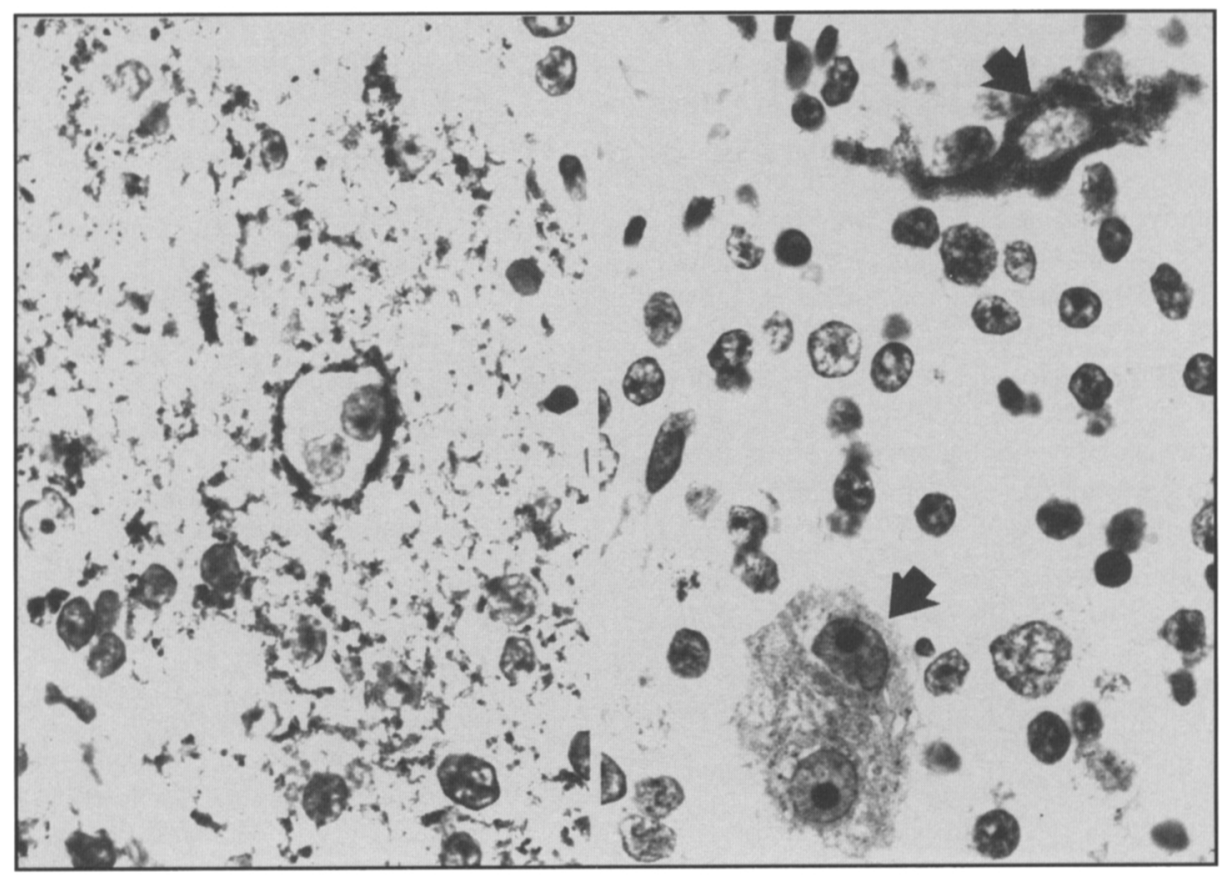

Figure 3: Left: Synaptophysin immunohistochemical stain illustrating the large binucleated cells and the small neurocytes with halo formation. Right: Chromogranin A stained only the large binucleated gangliocytes (arrows).

described a case of ganglioglioneurocytoma, hypothesizing its origin as a result of differentiation of a central neurocytoma into ganglioglioma with the trimorphic elements. ${ }^{9}$

Ganglioglioneurocytomas should be clearly distinguished from neuroblastomas with neuronal differentiation, or medulloblastomas with mixed neuronal and glial differentiation, as ganglioglioneurocytomas should have no primitive or anaplastic elements. Yamamoto et al. published a case of neurocytoma/gangliocytoma with leptomeningeal dissemination. This tumor has no glial component and as suggested by the authors it resembled neuroblastoma to some extent. ${ }^{10}$ It is also important to differentiate ganglioglioneurocytoma from the more common neurocytoma, where mature ganglion cells may get entrapped within the tumor as it infiltrates the native elements. The ganglion cells in this case would be surrounded by reactive astrocytes forming the so-called satellitosis phenomenon. This is why, with the exception of Nishio's case, some recent reviewers would doubt that a tumor originating from gangliocytes and neurocytes does exist."
Unless future structural and molecular studies provide more convincing evidence, we think it is unwise to include central neurocytoma under the umbrella name of ganglioglioneurocytoma.

Ganglioglioneurocytomas appear to affect children and young adults aged 5-30 years with no gender predilection. Radiologically, the tumor is well defined, with calcification and partial enhancement to intravenous contrast. The reported locations of the tumor include intraventricular, lobar, cerebellum (this case) and spinal cord. The histopathology of these tumors is characterized by the findings in the present case; large mature binucleated neurons stain with synaptophysin and chromogranin A, small round cells with perinuclear halo stain with synaptophysin and proliferation of pleomorphic astrocytes. The prognosis of ganglioglioneurocytoma seems to follow that of other tumors of neuronal origin; good outcome is reported following surgical resection. Post operative adjunctive radiotherapy was not instituted in our case and serial radiological follow up was planned.

Table: Summary of the published cases of ganglioglioneurocytoma.

\begin{tabular}{|c|c|c|c|c|c|}
\hline Authors & No. of cases & Tumor name & Sex & Age & Site \\
\hline Nishio et al. 1990 & 1 & Ganglioneurocytoma & $\mathrm{F}$ & 30 & Intraventricular \\
\hline Miller et al. 1992 & 4 & Ganglioglioneurocytoma & $?$ & $\begin{array}{l}2 \text { child } \\
2 \text { adult }\end{array}$ & 2 spinal \\
\hline Giangaspero et al. 1997 & 5 & $\begin{array}{l}\text { Mixed } \\
\text { Neuronal-astrocytic }\end{array}$ & $\begin{array}{l}3 \mathrm{~F} \\
2 \mathrm{M} \\
\end{array}$ & $5-27$ & Lobar \\
\hline Schweitzer et al.1997 & 1 & $\begin{array}{l}\text { Neurocytoma \& } \\
\text { Ganglioglioma }\end{array}$ & $\mathbf{M}$ & 30 & Intraventricular \\
\hline Alkhani et al. & 1 & Ganglioglioneurocytoma & $\mathrm{M}$ & 25 & Posterior fossa \\
\hline
\end{tabular}


Many theories have been proposed for the genesis of this neoplasm. A suggested mechanism is that these tumors arise from a hypothetical single precursor cell. In the course of the evolution of this tumor, the cell would either transdifferentiate to form the different cell lines, or simply differentiate directly into the three types of cells. A subependymal progenitor cell could be that single precursor, as it was shown to have the capacity for potential neuro-glial differentiation. ${ }^{12}$ Further studies aimed at establishing the mechanism of differentiation through chromosomal analysis may be helpful in determining whether a similar gene defect is present in all three cell lines. In summary, ganglioglioneurocytomas are rare primary CNS tumors. We reported a case that occurred in the posterior fossa. Their benign histological features seem to correlate with a good outcome after surgical resection.

\section{REFERENCES}

1. Miller DC, Lang FF, Epstein FJ. Central nervous system gangliogliomas. Part 1: Pathology. J Neurosurg 1993; 79:859-866.

2. Nishio S, Takeshita I, Kameko Y, et al. Cerebral neurocytoma. Cancer 1992; 70: 529-537.

3. Eram S, Rosenblum M, Ho K. Neurocytoma in the cerebellum. J Neurosurg 1997; 87:100-102.
4. Constantini S, Houten J, Miller D, et al. Intramedullary spinal cord tumors in children under the age of 3 years. J Neurosurg 1996; 85:1036-1043.

5. Min K, Cashman R, Brumback R: Glioneurocytoma. Tumor with glial and neuronal differentiation. J Child Neurol 1995;10(3): 219-226.

6. Nishio S, Takeshita I, Fukui M: Primary cerebral ganglioneurocytoma in an adult. Cancer 1990; 66:358-362.

7. Miller DC, Kim R, Zagzag D. Neurocytomas: non-classical sites and mixed elements. J Neuropathol Exp Neurol 1992; 51:364(abstract).

8. Giangaspero F, Cenacchi G, Losi L, et al. Extraventricular neoplasms with neurocytoma features. Am J Surg Pathol 1997; 21(2): 206-212.

9. Schweitzer J, Davies K. Differentiating central neurocytoma. J Neurosurg 1997; 86:534-546.

10. Yamamoto $T$, Komori $T$, Shibata $N$, et al. Multifocal Neurocytoma/Gangliocytoma with Extensive Leptomeningeal Dissemination in the Brain and Spinal Cord. Am J Surg Pathol 1996; 20(3): 363-370.

11. Iantos PL, VanderBerg SR, Kleihues P. In: Graham DI and Iantos PL, eds. Greenfield's Neuropathology, Vol. II. London: Arnold, 1997: 661 .

12. Von Deimling A, Janzer R, Kleihues $\mathbf{P}$, et al. Patterns of differentiation in central neurocytoma. An immunohistochemical study of eleven biopsies. Acta Neuropathol 1990; 79:473- 479. 